Article

\title{
Between Pleasure and Resistance: The Role of Substance Consumption in an Italian Working-Class Subculture
}

\author{
Matteo Di Placido \\ Department of Sociology and Social Research, University of Milan-Bicocca, 20126 Milan, Italy; \\ m.diplacido@campus.unimib.it
}

Received: 8 June 2019; Accepted: 12 August 2019; Published: 14 August 2019

\begin{abstract}
In this article I discuss how illegal substance consumption can act as a tool of resistance and as an identity signifier for young people through a covert ethnographic case study of a working-class subculture in Genoa, North-Western Italy. I develop my argument through a coupled reading of the work of the Centre for Contemporary Cultural Studies (CCCS) and more recent post-structural developments in the fields of youth studies and cultural critical criminology. I discuss how these apparently contrasting lines of inquiry, when jointly used, shed light on different aspects of the cultural practices of specific subcultures contributing to reflect on the study of youth cultures and subcultures in today's society and overcoming some of the 'dead ends' of the opposition between the scholarly categories of subculture and post-subculture. In fact, through an analysis of the sites, socialization processes, and hedonistic ethos of the subculture, I show how within a single subculture there could be a coexistence of: resistance practices and subversive styles of expression as the CCCS research program posits; and signs of fragmentary and partial aesthetic engagements devoid of political contents and instead primarily oriented towards the affirmation of the individual, as argued by the adherents of the post-subcultural position.
\end{abstract}

Keywords: subculture; young people; identity; resistance; working-class; substance consumption; CCCS; critical cultural criminology; post-subculture

\section{Introduction}

Substance consumption has been widely recognized as an important aspect of identity for many young people [1-3]. Substance taking behaviors have been addressed as normalized [4-6] and both leisure and pleasure oriented [7-16]. As correctly underlined by Sanders [17] (p. 2)," ... the normalization thesis rejects explanations of drug use set in the discourse of pathology, and emphasizes instead the value individuals place on the use of illegal drugs, as well as how such drugs are used in the context of pleasure". Such thesis does not oversimplify substance consumption among youth by necessarily implying a homogeneous interpretation of it. On the contrary, it recognizes that substance consumption is a complex phenomenon, often interlinked with other cultural practices $[3,18]$ and always contextualized in specific locations, or scenes, in which material, cultural, and symbolic resources are accessed, produced, and reproduced [19-21].

Moreover, according to the normalization thesis the consumption of some illegal substances, specifically marijuana (the female flower of the cannabis plant) and hashish (the resin extracted from marijuana flowers), "...moved from the periphery towards the center of popular youth culture and is a very common feature of the leisure landscape" [17] (p. 2). As a consequence, the consumption of these substances plays a central role within young people's quest for security, identity, and expression [22] (pp. 348-350). By taking this into consideration, I focus on a non-deviant understanding of these 
cultural practices, in an attempt to unveil some of the functions of substance consumption in the context of changing youth cultures. More specifically, in the present article through a covert ethnographic case study of a working-class subculture in Genoa, North-Western Italy, I aim to discuss how illegal substance consumption of marijuana and hashish can act as both a tool of resistance and as an identity signifier for young people. In order to do so, I contextualize my study at the intersection of the work of the Centre for Contemporary Cultural Studies (thereafter CCCS) at the University of Birmingham [23-26] and more recent post-structural developments in the fields of youth studies and cultural critical criminology, such as the work of Ferreira [27] and Martin [28], among others. I will argue that CCCS-inspired scholarship and post-subculture developments, when jointly used, albeit apparently being contrasting lines of inquiry, may be able to shed light on different aspects of the cultural practices of specific subcultures as performed in different every-day contexts.

With this contribution I attempt to (a) reflect on the study of youth cultures and subcultures in today's society, with a focus on substance consumption as a meaningful cultural practice, where meaningful refers to the subculture's use of substance consumption as simultaneously a form of resistance and as an identity signifier for its members; and (b) to overcome some of the 'dead ends' of the opposition between the scholarly categories of subculture and post-subculture that characterizes contemporary debates in the field of youth studies. I will show that within a single subculture there could be a coexistence of resistance practices and a subversive style of expression, as CCCS posits, together with signs of fragmentary and partial aesthetic engagements devoid of political contents and instead primarily oriented towards the affirmation of the individual, as more recent post-structural developments seem to suggest. But before exploring these divergent positions in relation to youth subcultural practices in more details, I would like to provide an overview of the structure of this paper.

Firstly, the paper starts with a short contextualization of "the subculture versus post-subculture debate"; secondly, it follows the presentation of the theoretical framework where I discuss the main "sensitizing concepts" [29] that guided the analytical framing of the paper; thirdly, I introduce a few considerations regarding the nature of the fieldwork conducted and the overall methodology of the research; fourthly, I present the analysis of the case study proposed accounting for three dimensions: (a) the importance of the sites inhabited by the subculture; (b) the processes of socialization, with a focus on their confrontational and political features; (c) and the hedonistic ethos of substance consumption. As I will argue in more details in what follows, from an emic perspective these three dimensions of analysis seem particularly significant in shaping the sociocultural practices of the subculture explored; while from an etic perspective they function as theoretically and ethnographically thick representational devices able to bridge the often times problematic divide between lay and scholarly categories of analysis. Finally, the paper ends summarizing the main results of this contribution and the relevance of a joint reading of CCCS-inspired scholarship and post-structural developments in the field of youth studies.

\section{The "Subculture versus Post-Subcultures Debate"}

In this section I provide a short overview of the "subculture versus post-subculture debate", discussing some of the main tenets of each position respectively.

Started in 1964, the CCCS's research program was oriented towards the study of post-war youth subcultures. It prompted an overtly Marxist theoretical paradigm, which put social class at the center of the understanding of youth culture [19] (p. 62). Crucial analytical tools of the CCCS's research program were the intertwined concepts of subculture, largely inspired by the Chicago School's ethnographic explorations of marginalized groups (such as hobos, marijuana smokers, and street gangs) and the concept of resistance, inherited from the school's Marxist and critical heritage. According to the CCCS, spectacular styles and aesthetic cultural practices were seen as displays of resistance against the established social order and the moral ideology of bourgeoisie. The concept of subculture framed particular groups of youths and their 'confrontational' and 'performative' life-styles, their practices and beliefs, as substantially in antithesis with the values of 'mainstream' society, more 
specifically those of the post-WWII mass media and consumerism society. Following the same theoretical premises, the concept of resistance, as rightly underlined by Ferreira [27] (p. 66), was used by the CCCS. “ ... to describe a form of political culture characterized by collective attitudes of opposition, dissent and transformative practices in response to the subordinated structural position of working-class youth, expressed through the use of spectacular objects and performances connoted with anti-aesthetic canons towards bourgeois dominant taste." Else said, the CCCS framed subcultures and their practices of resistance in terms of class affiliation and in explicitly political terms. On the contrary, contemporary scholarship in the field of youth studies seems to partially neglect the concepts of social class, subculture and resistance. Instead this body of work is primarily concerned with the study of youth transitions [30-32]; and for what concerns more directly the context of this paper, with an understanding of youth cultures framed in terms of "post-subcultures" [33,34], "neo-tribe" affiliations [35,36] "lifestyles" [37-39], "pleasure citizens" [3] and "arts of existence" [27]. These later developments, albeit different from one another, share the intent to overcome what they perceive to be an obsolete and heuristically poor concept, the one of subculture. Their critique focuses especially on the supposedly confrontational and political character of certain subcultures, that is perceived by the post-subculture's adherents as substantially lacking. In fact, the purpose of these later developments in the field of youth studies, is to replace the concept of subculture with new definitions that mirror the highly commodified and individualized character of youth popular culture, and consequently the partial, fragmented, and elusive affiliations it enables $[27,28]$.

However, as Martin [28] (p. 129) underlines, despite the heuristic value of these later sociological analyses, such alternatives to the canonical notion of subculture may be criticized as providing simultaneously a celebration of consumerism and an uncritical view of consumer culture. Such critiques may be exemplified by Blackman's and Hesmondhalgh's [40-42] commentary of Bennett's [36] concept of "lifestyle", which considers the individual as an active consumer able to freely choose among a variety of identity options at her disposal. Nonetheless, as further argued by Shildrick and MacDonald [43], the possibility of a free cultural choice enacted with the sole purpose of self-actualization, a possibility articulated in the post-subcultural discourse, seems to remain a valid prerogative of dominant classes, and certainly a little more than a mirage for the disadvantaged and marginalized youth. As a consequence, and in accordance with others [19,28,41-43], I wish to underline the importance of revitalizing a certain line of inquiry characterizing the work of CCCS. This, I believe should allow the complexity and variegated backgrounds of today's youth cultural and subcultural practices to be fully appreciated. Moreover, it may also contribute to find ways to theorize about youth practices and every-day-life in ways that positively dilute the binary opposition created by the scholarly categories of, and debates about, subcultures, and post-subcultures.

\section{Theoretical Framework}

The theoretical framework proposed here is a joint critical reading of Ferreira's analysis of "arts of resistance" versus "arts of existence" [27] and of Martin's "critical cultural criminology" of youth [28]. The former is one among the many alternatives to the concept of subculture expressed by the post-subcultural discourse; while the latter functions as a bridge between the work of CCCS and later pos-structural developments in the field of youth studies. Let us now have a closer look at these positions respectively.

The first position, that of Ferreira [27] (p. 68, Italics in original), can be succinctly accounted for by the author's own words:

In my point of view, it is hard to find traces of a politics of resistance in contemporary youth scenes aesthetics as it was described by subcultural tradition of research, and even as it is being endless reconceptualized under some post-subcultural explorations ... I argue that the aesthetics claims made in the context of contemporary youth scenes are much more engaged towards the expression of a politics of existence, that is, the social recognition of a personal identity self-fulfilled and self-defined as singular, authentic, creative and free. 
Ferreira expresses here his skepticism towards the politically charged notion of subculture as it was theorized by the CCCS and related scholarship. As an alternative he posits that contemporary youth subcultural practices rather than being a form of arts or politics of resistance are instead closer to what he defines as arts or politics of existence. In fact, according to Ferreira [27] and in contrast with the CCCS and related literature, contemporary youth culture favours personal construction over collective expression, a single heterotopia over shared utopias and dystopias, particularistic over universalistic values, and an ethics of celebration over an ethics of contestation. In other words, youth cultures are framed as substantially individualized and individualizing.

Moreover, accounting for Ferreira' s [27] position, class or any other ideological criteria of belonging to a certain subculture are theorized as being dismissed by the youths, which on the contrary seek self-affirmation through looks and/or performances substantially devoid of political meaning. As a consequence, following this line of analysis it is somewhat accurate to talk about the emergence of a globalized youth culture in which aesthetic practices of consumption, reproduction, leisure and pleasure are intrinsically interrelated $[3,18,27]$; and where political and confrontational values remains on the background, if present at all. Here, youths are seen as developing cultural practices mainly oriented towards managing and exploiting the complexity of neo-liberalism and its imperative do-it-yourself ideology in the attempt to affirm themselves, or in other words, to self-actualize their identities in 'de-politicized' and individualistic manners.

In opposition to Ferreira's analysis I believe that the work of the CCCS remains relevant in a number of ways, most specifically in relation to its focus on social class and the resisting practices of subordinated groups. Although Ferreira's analysis [27] attempts to remain aware of the complexities and the multifaceted nature of contemporary global youth culture, it provides a rather homogeneous and idealized understanding of young people's ability to navigate the mechanisms of contemporary youth culture. In fact, according to Ferreira youths' primary concern [27] (p. 75, Italics in original) is "to make a work of art out of their lives, as authors and protagonists, they creatively design themselves and their existences as ways to achieve self-fulfillment (autonomy), self-discovery (authenticity) and self-distinction (individuality), and to mark their own spot into the world". However, the risk with this position is in overlooking the importance of social class, neighborhood, and spaces on young people's lifestyles and identity [19-21]. Instead it focuses closely on the supposed free choices that govern an emergent globalized youth culture, but it neglects the fact that the emergence of this globalized culture is not necessary an homogeneous phenomenon across national and sub-national cultures and subcultures.

The second theoretical position is Martin's [28] (p. 125) "critical cultural criminology" of youth. This position, due to its sensitivity to the capitalist environment in which youth cultures develop, change, resist and adapt, functions as a useful bridge between CCCS scholarship and later post-structural scholarship, such as that of Ferreira. Martin's "critical cultural criminology" repositions transgressive acts and more mundane activities, such as hanging out in the streets, in the context of 'consumer capitalism', as opposed to the notion of 'consumer culture' which is nowadays dominant in youth studies. This is an important methodological caveat, as it problematizes notions such as "global youth culture" and "individualization" in the light of the still existing relationships of production, consumption and domination that characterize neoliberal, capitalist societies. As Martin [27] (p. 125) stresses, 'consumer capitalism' “...indicates the persistence of capitalist relations in western societies, albeit relations of consumption now increasingly replace relation of industrial production" (Italics in original). In other words, the main contribution of this approach rests on its placement of cultural and subcultural analyses in the context of consumer capitalism, thus repositioning issues related to class, inequality, place, and locality at the center of the fields of youth studies and cultural studies [19,28,41-43]. Such an analytical framework may in turn justify the resort to subcultural theories of resistance when attempting to account for the experience of marginalized and disadvantaged youth. In fact, in contrast to the kind of analyses exemplified by Ferreira's [27] contribution, not all young people have equal access to the same material, cultural, and symbolic resources that make up contemporary global youth 
culture, seen by the proponents of the post-subcultural positions in terms of individualized, value-free, and ideologically — not to say substantially a-political—poor choices. On the contrary, I argue that the study of youth cultures and subcultures needs to be problematized on the ground of actual class affiliations of the young people we interact with when conducting empirical inquiries.

Summarizing, combining Ferreira's [27] and Martin's [28] analyses sheds light on how the concepts of subculture and resistance-not to say of social class—are still well-suited theoretical lenses to decipher young people's differentiated attempts at seizing control over their lives. This does not imply a blind subscription to the CCCS research program, so much as a re-adaptation of its central themes within the framework of contemporary youth culture. In the context of this paper, for instance, I theorize the concepts of subculture, resistance and social class in post-structural terms. Subculture is therefore to be intended as a grouping of subjectivities sharing a lifestyle characterized by transitional, dynamic, and plausible acquirable identities [44] (p. 1081), in which shared cultural practices are collectively enacted as micro-political meanings [45]. Resistance, coupled with neo-Marxist traits, is defined as partial, fragmented, temporary, and transgressive rather than revolutionary and totalizing. Yet resistance, in line with Martin's [28] "critical cultural criminology", is still oriented towards " ... a highly complex system of late capitalist neoliberal global structures and ideologies that create inequalities and poverty in the world" [44] (p. 1085). Finally, the concept of class is defined as "...a reflexive game, through which people acquire capital and resources, and build up identifications and value for themselves as "individuals'" [20] (p. 58) and I would like to add, as members of specific groups. In other words, taking on board the concepts of subculture, resistance and social class, does not dismiss entirely the analytical acumen of the post-structural developments that characterize the "subculture versus post-subculture debate", but on the contrary it re-positions the work of the CCCS as contemporary rather than outdated.

In the next section I briefly introduce a few methodological reflections before proceeding with the description of the case study explored.

\section{Fieldwork and Methodology}

Genoa is a city of 844.957inhabitants [46], located on the North-Western Italian coastline. Developed on a strip of land caught between the Ligurian Sea and the Ligurian Apennines, Genoa is primarily a seaport. The historical, economic, and sociopolitical traits of the city are intrinsically bounded to its maritime roots. As Roberto Scaramuzzino [47] (pp. 131-132) underlines, the shipyard industry played a fundamental role in the economic post-WWII upturn, attracting workforce from both Northern and Southern Italian regions. In the 1970s, an economic and demographic downturn followed, only partly reversed in the 2000s [47] (p. 132). Moreover, Genoa is also known for its long-standing communist and anarchist legacies, traditionally connected with the 'camalli' movements (maritime workers) and by a lively anti-institutional political scene [48].

I was born and raised in Genoa, where I lived until my early twenties. Such a biographic contingency allowed me to easily access the field through my contacts with the members of the subculture, as I was myself one of its peripheral members during my teens. The subculture discussed is a youth working-class subculture characterized by both recreation and problematic substance consumption of marijuana and hashish and micro-level drug dealing of the same substances. This subculture is also characterized by a substantial disdain for institutional politics and the capitalist system of production and consumption (more on this in the following pages). Although to provide a clear-cut differentiation between recreational and problematic substance consumption is out of the scope of this paper, a short discussion is due. This distinction is often the expression of specific ideologies towards illegal substances, and thus arbitrary in nature, rather than an incontrovertible 'scientific' fact. In the context of this paper I define the former alongside the tenets of the normalization thesis [4-6], as primarily leisure and pleasure oriented; while the latter is understood as those forms of substance consumption that may lead-with more probability than the mere consumption of marijuana 
and hashish—-to poor health outcomes, both physical and psychological, and to increasing stigma and social isolation of the consumers.

With regards to the age of its members, the subculture is composed by three main age cohorts: (a) 15-23; (b); 24-30; (c) and 30+. Most members of the subculture belong to the first two age cohorts, with a marked majority belonging to the second one. The third age cohort consists of a handful of individuals that are recognized as the most 'expert' members of the subculture and which also act as its main illicit substance providers, or dealers. The size of the subculture is rather flexible, as are its boundaries. Thus, an on-going turn-over of its participants can be observed, especially on the periphery of the group. For these very reasons it is quite difficult to provide an estimate of its size, but an 'informed guess' based on my observations seems to suggest that it counts up to 45 to 60 people. Yet those with whom I spent most of my time in the field and with whom I built a closer relationship amount to a subgroup of around fifteen individuals. It is important to note that those that I interacted more closely with-as much as most of the subculture's members at the time of my explorations-were either unemployed (with and without welfare benefits), high-school students, or only partly engaged in non-secure employment. This testifies to the working-class character of the subculture, and to the knowledge currently at our disposal regarding the relationship between class, education and employment levels [49-51]. Additionally, the older members of the subculture (30+) were well known for their past involvement within the hooligan scene of one of the two main football clubs of the city-again linked in literature with working-class groups and subcultures [52-54] -and as we will see in the commentaries below, openly advocated for a 'life-style' based on the rejection of the values of bourgeois sobriety and its working ethic of self-sacrifice. To my knowledge only two members of the subculture were enrolled in different courses at the University of Genoa (nursing and engineering), but one dropped out before the end of the program (the member studying engineering). By the end of the fieldwork, these individuals were two out of the only three members of the subculture that were relatively steadily employed. Many of the individuals belonging to the subculture relied on small-scale, street-dealing of hashish and marijuana as a source of income, mainly carried out within the borders of the two sites explored. Moreover, the subculture at the time of my exploration was primarily composed of Caucasian male individuals. However, the gender composition of the subculture I portrayed in the present work may partly be explained by the fact that I established closer links with male members. Such a contingency undeniably influenced the re-enacted voices and the silenced ones. In fact, the ethnographer's sexuality is not a neutral matter while doing fieldwork [55].

More specifically, my access to the field was granted by a gatekeeper, Raffaello (pseudonym), a 24-year-old male member. I knew Raffaello since our childhood as we grew up in the same neighborhood, went to the same schools and had some friends in common. I contacted him and we met one afternoon of the Winter of 2014. We drank coffee and chatted in his mother's kitchen, updating each other regarding the main changes occurred in our lives since high school. I was finishing my masters in the social sciences in a fairly good university abroad while he was still highly involved in the subculture, as both a consumer and a small substance provider. He was also working part-time as cook help, especially during the week-ends. It is in that occasion that I informed him about my current work on underage substance consumption and social services provisions, and most importantly about my research interests on substance consumption and youth subcultures. We then begun 'hanging out' together 'regularly' every time I was in town (two to three weeks per year) for the following three years.

The empirics presently discussed are composed of several field visits (16 in total) carried out between the Winter of 2014 and the Fall of 2017, with a peak of visits in the period ranging from the end of 2015 to the beginning of 2016 (9 visits). In other words, this research can be considered an expression of "focused ethnography" [56], namely of an approach to fieldwork characterized "by short-term field visits", "an interest in a specific research question" and "a researcher with insider or background knowledge of the cultural group" explored (p. 4). During these field visits I relied almost exclusively on head notes although when the situation allowed it I typed schematic notes and sketches of conversations on my mobile device (phone). Otherwise, after each field visit I wrote down, first 
in forms of jottings or sketches and right after in greater details, the most important happenings or conversations of the day. Moreover, it is important to say that my field notes are somehow inextricably linked with self-reflexive explorations, in the guise of a personal diary, and move freely between the realist, confessional and evocative writing styles [57]. Also, I often begun to note down and explore plausible theoretical implications while transcribing the field notes. In this sense, it appears clear how the divide data/theory, or data collection phase/analysis phase does not hold entirely true in the case of this research. I applied a "data-saturation logic" [58] to the research, which signifies that I interrupted the field visits once my observations begun to repeat themselves in terms of contents and plausible theoretical and analytical considerations.

I adopted a "covert participant observations methodology" [59], namely a form of research where the researcher participates in the cultures, groups or organizations he or she is observing whilst hiding his or her true identity as a researcher. Covert participant observations have a long-standing and contested history within the social sciences in general and sociology more specifically. For the moment it is enough to notice how during the 1950s and 1960s, the School of Chicago popularized this methodology through a number of studies [60], discussing for instance the every-day-life of taxi drivers [61], factory workers [62], or jazz clubs [63]. Other notable studies that testify to the relationship between covert participant observations and sociological research are: Humphreys's [64] study of public bathrooms used for secret homosexual relations; Bernstein's [65] study of factory workers; Goffman's [66] groundbreaking research on 'total institutions'; Parker's [67] study of gangs of adolescent boys; and more recently, Pearson's [68] research on football hooligans and Alice Goffman's [69] study of young men on the run from the police.

To summarize the pros and the cons of this method, covert participant observations have been praised for their ability to study organizations, institutions and groups that otherwise-through overt methodologies - would not have guaranteed formal consent to the research; for their ability to provide unobtrusive observations $[59,70]$ and contribute to the study of specific groups and the demystification of their supposedly 'deviant' behaviors. For example, Goffman's [66] research helped to see mental health patients as individuals whose rights were systematically violated; while Humphreys's [64] study contributed to the demystification of homosexuality as a pathology. However, covert participant observations have also been criticized for depriving informants of the right to refuse participation or to withdraw from the research study [59]; for violating the "principle of informed consent" [71] (p. 252); and even for the dubious ethical validity of the data collected [59]. In fact, the data collected through covert research methodologies are usually gathered in situations where the participants being observed may engage in behaviors they do not wish to be recorded [69].

In other words, covert participants observations offer a number of advantages but also some important ethical shortcomings, some of which are also shared by overt research methods. As a consequence, I agree with van Amstel [70] and with Roulet et al. [59] in conceptualizing research methodologies not as either covert or overt-or for that matter as ethical or unethical-but on a continuum between these two poles. For instance, in the case of this research Raffaello knew about it, as the good practice of overt research methods would have it; while most of the subculture members did not, in line with the covert nature of the research. For them, my presence in the field was simply 'taken for granted' as the presence of a 'friend of a friend' that, by the way, was also already known in the subculture for his previous involvement in it as a peripheral member. Therefore, this research can be considered an example of the sometimes "ambiguous consent" [59] of participatory research.

I then decided to continue the research following a covert method of data collection for several, interconnect reasons: firstly, as argued by Leo [72] and Lauder [73], this is oftentimes the only way to study 'deviance'. In fact, as further argued by Roulet et al. [59] (p. 492) "covert participant observation can provide access to institutions or organizations that would otherwise remain excluded from researchers"; secondly, I was concerned for my security and I did not want to upset the members of the subculture, in particular the older ones, as some of them are also well-known for their 'physical' and 'intimidating' manner of resolving disputes. For instance, during my field work I 
witnessed arguments escalating into physical confrontations in more than one occasion. Of course, considering the 'confrontational' nature of the interactions within the subculture, surely also related to the hooligan heritage [52-54] of some of its members, I feared a confrontation if they would have come to know my identity as a researcher; thirdly, a covert participant observation strategy allowed to gather data in a non-obtrusive manner. Although this might have been possible through overt research methodologies—see for instance Lalander's [74] study on heroin use in a Swedish town-the convergence between illegal activities (e.g., substance consumption and dealing) and the hooligan roots of some of the member of the subculture, were reasons that pushed me to conceal my identity as a researcher; fourthly, in line with a "consequentialist perspective" [59], I considered that the benefits of the research outweighed the costs of secrecy and to a certain degree of the 'deception' imposed to the participants $[75,76]$. In fact, even though I situated this research at the intersection of the scholarly debates about youth cultures and subcultures, I also attempted to discuss the normalization of marijuana and hashish consumption, inquiring into alternative forms of socialization without framing them in 'deviant' terms, a subject I shall develop at some length in the conclusion of the paper; fifthly, in line with a "situated ethics approach" [59], I tackled the ethical considerations related to research praxis as an ongoing social practice highly shaped by contextual factors rather than by universal codes of conduct [77]. As argued by Roulet et al. [59] (p. 503) "[i]n a number of empirical contexts, it is impossible to "take a side" (i.e., determine what is right and wrong), considering the complex web of connections and motives... This is especially true in the contexts that are harder to access for researchers". As a consequence, a situated ethics approach posits that the covert observer engages in constant reflection on the morality of his positioning and actions in the field, a practice I made sure to take at heart during my fieldwork. In fact, although a certain degree of secrecy and deception has been maintained towards most members of the subculture, the subculture's members identity, as much as the name of the locations explored have been fully anonymized and pseudonyms used in all circumstances. Moreover, as much as my reflexive practice and self-awareness allowed for, I attempted to avoid discriminatory and stigmatizing expressions such as "drug use", "drug addict", and "drug dealer" and I avoided recording any substance dealing activities in my field notes. Finally, it is important to state that I have not engaged in substance consumption myself-or for that matter dealing-during the time frame of the research. During the research I was not consuming marijuana or hashish any longer, although not out of a moralistic attitude or a puritan research ethic, but simply on the ground of personal reasons (recovery from a recent head injury obtained while boxing).

This last remark brings us closer to the discussion of my positioning in the field, where I assumed a liminal position between the roles of the observer and the participant. I was neither a simple observer, as I did not sit aside taking notes while the every-day-life of the subculture unfolded in front of my eyes; but neither I was "fully immersed" [78] in the life of the subculture, insofar as my participation did not include the central practice discussed in this paper, namely marijuana and hashish consumption. On the contrary, I participated in a series of other leisure activities, such as chilling in the sun, conversations, playing football, dancing and so on and so forth. Therefore, I see my positioning in the field as the one of the 'informed observer': I was myself socialized to the norms, values and practices of the subculture as in the past I was one of its peripheral member, but I was also substantially 'other' to it during my field visits due to my newly acquired identity as a social scientist.

Let us now move to an exploration of the ethnographic descriptions composing the case study here presented. More specifically, I will firstly explore how sites, or specific social spaces, represents the confrontational and working-class ethos of the subculture explored; secondly, I will describe how the processes of socialization into the subculture, with a focus on substance consumption, are inherently relying on an oppositional culture (what Ferreira [27] addresses, dismissing them as substantially absent, "arts of resistance"); thirdly, and on the contrary, I will also discuss how the hedonist ethos of the subculture does resonate with an understanding of youth culture and subculture as substantially devoid of political significance and primary concerned with individuals' self-actualization and performativity. 


\section{The Heart of the Subculture}

As I underlined in the theoretical section of this paper, specific spaces or sites where young people hang out, are the primary components to be analyzed in relation to subcultures' lifestyles and processes of identity construction [19-21]. Put otherwise, contrary to the tendency of post-subcultural positions, I argue that the importance of social class, and as a consequence of neighborhood and spaces for young people's lifestyles and identity cannot be overlooked [19-21]. In fact, as Ferrero Camoletto and Genova underline [79], the use of urban spaces or in their words a "stylization of space", represents a constitutive and distinctive dimension of some youth cultures, where cultural and subcultural practices are not merely performed but also spatially inscribed in a network of spatial, material and symbolic relationships, which, as in the case of the subculture here explored can be charged with political meanings. In this section, I firstly introduce the two sites where I carried out my ethnographic observations, the Pearl and the Occupied Warehouse (both pseudonyms) using extracts from my field notes. Then I proceed to a discussion of the importance of these locales for the subculture and its practices.

The Pearl is hidden, inaccessible if you do not know how to get there. It is located in between two small fishermen harbors, one of which is a symbol of the city, often portrayed in prints and postcards. These harbors are characterized by the typical Ligurian clusters of colorful houses. On sunny days, these places attract crowds of locals and tourists on their shores. This site is a secret pearl right next to the sea. Consumers and dealers have been gathering here for a long time, year-round except for the summer, when the place becomes a beach resort. The site is a historic backdrop for Genoan substance consumption, dating back to at least the 1980s. Here the members of the subculture find a safe environment to carry out their activities without the need to hide. They are the undisputed owners of the place, even if unaware passers-by are a few meters away, and yet so distant. All you have to do to see people belonging to mainstream society is go up a staircase that connects the site to the closest trails, or follow the path next to the cleaves along the shore. (Field note January 2016)

The Occupied Warehouse is a former salt warehouse, with thick stone walls and high shabby ceilings. It is a social center, an occupied space for youth sociability and grassroots political activism. Inside, big lettering on the walls speaks of political involvement. In red, black, and white, 'Genoa is Anti-Fascist' takes up a 12- to 15-m-long wall, and on the other side, on a smaller scale but still big and visible, 'Resistance' reminds the looker about the nature of the place. Political struggle is embedded in these walls. This merges with street art murals covering the whole place. Here the members of the subculture gather to spend their free time, mostly at night-time. (Field note March 2015)

The first site is located on the Eastern side of the city, just next to one of the most popular tourist spots of Genoa. It is a very typical, colorful cluster of houses perched on the blue sea, but it is also close to the few traditional working-class areas to the east of the city, where most members of the subculture reside. These neighborhoods, originally farmers' villages peripheral to the city, saw a progressive transformation and inclusion into the urban fabric. This as a consequence of Genoa's industrial development, the excessive overbuilding that characterized its urbanization processes and the increasing migration of work-force from Italian Southern regions to its Northern Industrial Triangle (Genoa, Turin and Milan), especially in the aftermath of WWII [47]. The second site is located on the Western side of the city, just next to the Port. This area too was previously constituted by fishermen and farmers communities, and was known for its beautiful shores. However, starting from the middle of the 18th century, the area gradually morphed into a shipyard pole first and then into an industrial one devoted to the refinery of heavy metals. Today, long after the decline of the metallurgical industry, these areas continue to be inhabited by strong clusters of working-class communities next to migrants groups that in the last few decades moved to Genoa as a consequence of the city's increasing request for domestic care of its elderly population [80-82]. Finally, the street where the second site is located is one of the most well-known in the city for street prostitution. 
The Pearl can be classified as an "open drug scene", defined as "...a relatively numerous concentrations of people using drugs in a location within the urban fabric" [83] (p. 25). Even though the subculture took control of it mainly as a place for small-scale dealing and substance consumption, it is a public space in its nature-yet people who do not explicitly belong to the subculture rarely venture into it. Occasionally, as I had the chance to observe several times, 'outsiders', often tourists, come to the site with the intention of sunbathing and relaxing, but they turn away upon realization of being observed with suspicion by the members of the subculture. Under such circumstances, the first concern of the members, mainly the eldest and most established ones, which are also the crucial dealers of this site, is that these unknown individuals may be undercover police officers. Their concerns seem justified by the fact that the Pearl has been the object of several police operations in the last few years, some ending in penal persecutions for certain subculture's members.

As far as the Occupied Warehouse is concerned, its location within an old building, in a relatively disused area of the city, means that most of the activities carried out in the site are concealed from the eyes of unintentional witnesses. Moreover, its political character is striking, being a self-managed, independent, and anti-institutional space of political activity, namely a "centrosociale" [84,85], translated in English literature as "political squat" (see for instance Genova [86] and Martínez López [87]).

However, both sites can be said to almost constitute a parallel world, where the routines and norms of 'mainstream society' are replaced by the ones of the subculture. Here, the duties of 'normal' people are suspended, resisted, and inverted [45]. In fact, both sites are characterized by the establishment of clear boundaries, in geographical, architectonic, symbolic and affective terms between the inner world they define and 'mainstream society'. In the first site, for example, physical boundaries are represented by the natural elements of the sea and cleaves. Such boundaries strengthen the symbolic and affective boundaries of the site, and function as a metaphor for the difference between the norms and values promoted by the subculture and the ones of 'mainstream society'. This sentiment is further reinforced by the fact that even though both touristic and residential areas are a few feet away, the Pearl is almost completely invisible. A very similar consideration could be made in relation to the second site, with the difference that the main boundaries of the Warehouse are established by the building in which the occupied social center is located and not by natural elements such as cleaves and the sea.

Here, the concept of "affective atmospheres" [88] defined as the affective/emotional features of a given space and its generative potentials to arouse affects and emotions in the bodies of those who move in them, is useful in theorizing how specific social spaces such as the Pearl and the Occupied Warehouse, are particularly conductive of certain affective and emotional tones. In fact, although this concept have been criticized as deterministic [89], namely for implying a linear and causal relation between specific spaces and emotions, it remains a useful heuristic tool through which to inquire into how the processes and the practices studied, in this case substance consumption of marijuana and hashish, always unfold into specific spatial configurations. Moreover, the Pearl and the Occupied Warehouse can be addressed as examples of "ethical scenarios", defined by Rose [90] (p. 194) as "the diverse apparatuses and contexts in which a particular relation to the self is administered, enjoyed, and assembled". This signifies that these sites, considering their specific locations within the urban fabric of the city, their geographical, material, and symbolic boundaries, and of course the affective charge that the subculture's members relate to them, become the primary contexts in which the subculture's members are socialized to its norms, values and worldviews. For example, murals such as those recalled in the previous field note, 'Genoa is Anti-Fascist' and 'Resistance', and the constant reference to symbols related to the anarchist and Marxist ideological backbones of the place, as much as other symbols such as the Rasta flag and the marijuana leaf [86] (p. 14), function as important elements of the socialization processes of this subculture.

In other words, as much as through the concept of affective atmospheres we may grasp the importance of the spatial and architectonical configurations of the subculture in influencing the emotional landscape of their members, through the concept of ethical scenarios we are reminded of how these spaces are first and foremost locations where the members are re-educated to perceive 
themselves and the surrounding world in alignment with the norms, values and worldviews of the subculture. I will expand on this latter point in the next section. For the moment, I would like to further underline how such radical divisions between subculture's places and practices and those of 'mainstream society' is crucial in order to legitimize subcultural practices whose values seem to be based on the degree of distance from institutional practices and prescribed behaviors.

Following a classical Durkheimian reading, the sacred is always determined in opposition to the ordinary or the profane [91]. In reference to the Pearl and the Occupied Warehouse the sacred is exemplified by the sites themselves and by the ritualized substance consumption that unfolds there; while the profane is represented by the norms of 'mainstream society', both in legal, moral and social terms. According to this reading, the ritual consumption of substances acts in both sites as a practice of demarcation between the sacred and the profane and substance consumption becomes a ritualized practice able to provide a meaningful alternative readings of reality, and of what is deemed legitimate or even auspicable for the members of the subculture. Here, the sacred, namely the substance consumed within the boundaries of the sacralized sites, is the very object of the ritual itself; in other words, the sites become the hearts of subculture's practices and group identity, on the ground of their bordering or 'othering' function between the members of the subculture and other individuals. In fact, as Goffman's [92] 'Behavior in Public Places' poignantly underlines, being present in the subculture' sites primarily signifies sharing and participating in the practices and rituals of the subculture itself, which in turn signifies becoming a member.

\section{Socialized to 'Other Rules'}

Socialization processes are pedagogical moments, both formal and informal, where individuals acquire specific worldviews through interiorization, meaning ascription, and identity formation processes characterized by knowledge transmission, acquisition and apprenticeship of specific practices [93]. In the case of the subculture explored, we could say that the members are socialized to the familiarization with substance consumption by learning about the values connected with its use and the rules that regulate its consumption. These processes are akin to what is delineated by Howard Becker in his article 'Becoming a Marihuana User' (1953) [7] and later in his study of 'deviance', 'Outsiders' (1963) [94]. In 'Becoming a Marihuana User' he posits that "[a]n individual will be able to use marihuana for pleasure only when he (1) learns to smoke it in a way that will produce real effects; (2) learns to recognize the effects and connect them with drug use; and (3) learns to enjoy the sensations he perceives" [7] (p. 235). In his sociological classic, 'Outsiders', he approaches 'deviance' as the result of a labelling process initiated by a certain group (e.g., 'mainstream society') and then subsequently accepted and reinforced by the 'deviant' group (e.g., subcultures of various kind). The central tenets of his "labelling theory" are: (a) that individuals' sense of self is influenced by the terms used to describe and categorize them by 'other groups'; (b) and as a consequence that alternative modes of socialization become possible only on the ground of specific "othering processes" [94]. In other words, and in the light of the empirical case here discussed, this signifies that the members of the subculture learn that substance consumption is valued both in itself, for its hedonistic and subversive character, and as a practice contextualized within broader countercultural and political practices that distinguish the subculture and its members from the rest of society.

For now, let us focus on the actors that dispense, both implicitly and explicitly, the how-tos of substance consumption. Although a few individuals could be defined as the long-timers within the subculture whose leading role is overtly recognized by all members, the process of socialization seems to be rather non-hierarchical and horizontal. This point is particularly important, especially in reference to other praxeological studies on Italian youth subcultures [86,95]. For example, in his attempt to delineate a number of core features in contemporary youth cultures in the Italian context and in fields as diverse as music, sport, politics and religion, Genova [95] (p.85) underlines, "[w]ithout forgetting the peculiarity of each field, [that] it is possible to say that these processes [of socialization] are more and more 'horizontal', developing among peers, with each actor involved both as transmitter and 
receiver". Else said, the socialization to substance consumption within the subculture here explored seems to follow, at least roughly, the same mechanisms of socialization identified in other subcultural fields, particularly in the case of other Italian youth subcultures.

However, zooming into the socialization processes of the subculture here discussed, this horizontality means that less experienced members have a say in influencing each other and younger members of the subculture. Implicitly, socialization to substance consumption happens through the processes of learning by witnessing the long-timers' example and embodiment of the subculture values and practices. Explicitly, it takes place through narrations and actual formal teaching moments. An experienced member suggesting a less experienced one to use a smaller dose of a rather strong kind of hashish or marijuana, or to consume it in a specific moment of the day according to its relaxing or exciting effects, are examples of explicit circumstances of socialization.

But a horizontal model of socialization does not imply the lack of hierarchies within the group. For example, the spatial dispositions of members within the site reflects an internal distinction in the subculture itself, between 'rookies', namely the youngest and newly arrived members, and long-standing, more experienced ones. As I recorded in the field notes after a visit to the Pearl:

The rookies are sitting among themselves and the older consumers sit together. They even sit in different sections of the site. Some kind of hierarchy seems to be in place among groups, based not only on age; perhaps experience matters the most. That's why a small dealer like Cezanne (pseudonym) is welcome and well considered even though he is rather young. The older members connect easily with him. From the way Cezanne speaks to the older members, I can also notice he has earned some kind of status among them. He is recognized. (Field note February 2014)

Moreover, in the two sites examined members are socialized to substance consumption in different ways. In the first site, which I have identified as an "open drug scene" [83], consumption is framed as the central practice of resistance and as an attempt to call oneself out of society and its rules. In the second site on the contrary, substance consumption is a practice nested among others. It is interesting to notice that one of the sites-the Occupied Warehouse-has in fact repeatedly appeared in local and national press during the period of my research as a locus of bottom-up, democratic practices and alternative cultural production. Its autonomy, independence, and anti-institutional character were described by these journalistic pieces-that I do not quote directly simply in order to maintain the anonymity of the place - as able to offer alternative models of socialization compared to the ones of 'mainstream society' and its institutions. In fact, the Warehouse is primarily a self-organized, open place, where decisions are taken in autonomy from institutions and often in direct opposition to them, and where the 'line of action' is decided by all the participants involved in its assemblies, at least in principle (for more detailed analyses of the social dynamics of "social centers" or "political squats" in the Italian landscape see [84-86]). As a consequence, it is only by being aware of the overall political and cultural commitments of the Warehouse that we can contextualize substance consumption as a further identity marker, capable of strengthening the resistance attitude and political identity of the members of the subculture.

In this respect, it is interesting to notice how the moments of both formal and informal pedagogy carried out by long-term members of the subculture, or using Bourdieu's analysis of the two modes of cultural circulation [96], the "didactic mode" and the "experiential mode" of knowledge transmission, tend to be different in the two sites. In the Pearl the 'teachings' are merely oriented towards the acquisition of safe consumption and dealing patterns so as to maximize pleasure and economic return; in the Warehouse the 'teachings' include a broader array of practices that range from learning how to play music to learning how to stand clashes with the police or other political groups, such as right-wing extremists. In both sites however, members are socialized to what may be described as a confrontational culture towards the State and those who, in their eyes, represent repressive institutions. Members seem to develop a particularly critical stance towards policing actions targeting political activism and substance consumption and towards the neoliberal imperatives of protestant working-ethic and consumerism which they consider the cornerstones of capitalist societies. This confrontational 
style, which accounting for the CCCs is one of the cornerstones of post-WWII subcultures [23-26], emerges clearly, together with its working-class heritage and rhetoric, as a distinctive character of the relationship between the subculture explored and authorities. On the one hand, many narratives of the members are focused around their experiences of avoiding confrontation with the police or avoiding legal consequences for possession or dealing of illegal substances; while on the other hand, specifically in the context of the Warehouse, members may idealize confrontations with the police, especially within demonstrations and political actions, as something legitimate and of crucial importance in defining their identity as non-institutional political actors.

These considerations seem to be supported by the findings of other studies conducted on Italian youth subcultures [84-86]. For instance, Genova [86] (p. 15), in his study of political participation in non-institutional settings, underlines the following:

Similarly, all the activists share the belief that institutional and totally legal forms of social, cultural and political intervention and participation cannot be effective instruments of social change. Two main alternative strategies are thus identified: On the one hand the experimentation and the diffusion of cultural styles and lifestyles characterized by practices and models alternative to today's dominant ones; on the other hand, the emergence, growth and diffusion of different forms and cleavages of protest, with the perspective of a general radical social conflict which leads to a crisis of the present institutions and structures of power.

In the same guise, the subculture here explored shows signs of these two strategies, namely of a cultivation of practices and worldviews that are antithetical to the one of 'mainstream society', such as substance consumption of marijuana and hashish and small-scale dealing; and "the emergence, growth and diffusion of different forms and cleavages of protest" that is to say, following the language used in this paper and in line with the CCCS' literature, its overall confrontational culture.

\section{Hedonism: Between Chilling and Catharsis}

Another crucial element that plays out within the subculture is its hedonistic ethos in relation to substance consumption [7-16]. Consumption patterns are strongly leisure and pleasure-oriented, whether merged with some sunbathing or slow-pace football as in the case of the Pearl, or taking place during cultural events such as concerts in the case of the second site. The practice of smoking while relaxing under the sun is often referred to as chilling out by the members of the subculture, an activity both therapeutic and diametrically opposed to what they perceive to be the unhealthy, forced, sped-up rhythms of contemporary society. Upon arrival at the Pearl it is common to find most of the members either chatting or laying around comfortably on the platform at the center of the site, or in the cleaves around it.

Both young and older members are smoking and drinking beer. The beers are passed around, as are the joints. Both are shared. The ritual does not differ if not for the preparation. A beer must simply be opened, while a joint implies that the substance has to be crumbled, mixed with a cigarette, rolled and only then smoked. It might take a few minutes. And the procedure implies being equipped with rolling papers, longer than the regular ones used for rolling cigarettes, and a piece of cardboard to make a filter for the joint ... smoking, especially, seems to be the main preoccupation of the members, as it emerges from their constant talking about it. (Field note March 2014)

Felix (pseudonym) sits on the side while we are playing some Olandese (Dutch football), a game where people pass the ball to each other trying to keep it from hitting the ground. I give him a look, as he inhales deeply after a long puff to his joint. Bare feet and naked torso, he lies on his back under the mild Spring sun. (Field note April 2016)

Surprisingly, music whether live or reproduced through technological devices does not play a central role within the practices of the subculture, at least in the context of the Pearl. I have hardly seen 
anybody with a guitar or any musical instrument or even with portable speakers. On the contrary, in the Warehouse music is a constant presence: not only it is consumed and enjoyed but it is also produced. A few members of the subculture are in fact disc jockeys (DJs) and play roots, reggae, dancehall, and different declinations of electronic music. Usually, they open concerts or music performances by major artists organized at the Occupied Warehouse, as the site functions also as a catalyzer for the international underground music scene, hosting artists from UK, France, Jamaica, and Germany. The music may vary greatly from time to time, but it is tied together by an underground nature and by being explicitly within the cultural references of the subculture. Other genres proposed are indie-rock, hip-hop, and of course politicized music (see also Genova [86] for similar accounts in relation to Turin's political squats). In these occasions, the music is very loud and there is a constant, thick wall of smoke, as I recounted in my field notes.

The air is thick with smoke... The dance floor is a collection of individualities busy in finding their place between rhythm and smoke. People dance as they seek an ecstatic experience. (Field note April 2015)

The members of the subculture dance, smoke and, to a lower degree, drink. During electronic music concerts, together with the traditional substances of the subculture-hashish and marijuana-there is an overt consumption of other substances including LSD, MDMA, amphetamine, and possibly other substances that I could not distinguish from the aforementioned ones in terms of their role and effects. In this light, a mention to the "gateway hypothesis" [97,98], which posits that early experimentation with substances such as alcohol, tobacco or cannabis may escalate into more addictive and problematic substance taking behaviors in adulthood, is due. In fact, although the 'substances of choice' of the subculture are marijuana and hashish, there are also other substances that are consumed by the subculture' members. However, considering that these potentially more problematic patterns of consumption are only observed sporadically in the group under study, the central tenet of the gateway hypothesis should be approached here with a certain degree of caution. Nonetheless, an aspect that I have not been able to fully account into the present research, and that may at least partially re-vitalize the gateway hypothesis, is an inquire into 'what kind of adults' the subculture contributes to produce. Put otherwise, despite its confrontational culture, does the subculture produce socially conforming adults as its members age? Or on the contrary, do they tend to remain actively involved in the subculture and its substance taking practices? Or finally, do they move from recreational consumption and experimentation to a steady consumption of other substances such as LSD, MDMA, amphetamine or other substances? Of course, an answer to these questions would require a new study altogether.

Now, I would like instead to point out typical situations of the 'night-scene' of the subculture's life, as depicted in my field notes:

Around 12 o'clock the dance floor starts to get busy. Mainly men. Some people gather, or rather, they confine themselves next to the speakers. They wear jeans and black jackets. The difference between their clothing style and the colorful clothes of other people is striking. Some of them are shaved. They complain for the music, they say it is too slow. In between two songs, somebody screams: "Change the music! Faster!". Nobody seems to care. The music keeps on going. Smooth dub music. (Field note April 2015)

Music and consumption of hashish and marijuana almost seem the same thing. No boundaries. I shoot a look at the DJs. They seem to exemplify what I mean: big joints in their mouths and hands on the mixer. They move their bodies along the dub rhythms. (Field note April 2015)

Accounting for my observations, the cultivations of aesthetic values within the subculture, especially music consumption and production, is intrinsically related to recreational substance consumption of mainly marijuana and hashish. Moreover, also the clothing styles of the subculture's members seem to be more codified in the second site than in the Pearl. Here, beside the traditional casual clothing style of the subculture, together with politicized t-shirts and hoodies with the symbol of 
the Warehouse or other political symbols referring to both anarchist and Marxist ideological matrixes, it is common to see people dressed as skin-heads. These scenarios, namely the centrality of music within the cultural practices of the subculture, and its variegate dressing styles, is again a point of contact with the subculture investigated by Genova [86] in relation to Turin's political squats.

Moreover, Mellor's and Shilling's [99] (p.174) concept of "sensual solidarities" is pertinent in describing the forms of sociality typical of the subculture explored. These scholars define sensual solidarities as:

Consumption-oriented forms of sociality; bound up with corporeal absorption and immersion. They are based on the feelings, emotions and the effervescence which can derive from being with others (as opposed to simply discursively communicating with them).

However, Mellor and Shilling [99], in line with Maffesoli's [35] account of "neo-tribes" as much as Ferreira's [27] "arts of existence", underline that " ... the characteristics of kinship, neighborhood and friendship these solidarities are built on can soon disappear from their specific contexts" (p. 174). On the contrary, I argue that the fragility and transitional nature of the gatherings of youth subcultures must be evaluated through close empirical exploration, case by case. In the case of this working-class subculture the sensuous solidarities that characterize the joint consumption of substances such as marijuana and hashish, among other subcultural practices such as conversations, chilling, and music performances, seem to be expression of a deeper sense of belonging grounded in the subculture' class heritage and confrontational culture, and not merely in its fleeting hedonistic practices. This becomes especially visible when paying attention to the politicized nature of the spaces inhabited by the subculture and its processes of socialization. However, more research (both in the guise of observations and interviews) is needed in order to fully support reflections such as this one.

Finally, it is possible to underline that while in the case of the Pearl the members of the subculture are displaying a rather chilled-out modality of consumption, in the case of the Warehouse-influenced by a different atmosphere and by music-substance consumption becomes increasingly ecstatic and cathartic in character, although a chilled-out approach to consumption is not totally absent.

\section{Discussion and Conclusions}

In this article I attempted to problematize the "subculture versus post-subculture debate" through the ethnographic exploration of a case study composed of an Italian working-class subculture where substance consumption plays a central role. More specifically, I have focused on (a) the importance of the sites inhabited by the subculture; (b) its processes of socialization, with a focus on their confrontational and oppositional features; (c) and the hedonistic ethos of substance consumption. In this final section, I would like to briefly summarize the results of these ethnographic descriptions and trace a few conclusive remarks.

Firstly, an appreciation of the sites where the subculture moves and thrives has been described as an invaluable aid in order to understand the network of spatial, material, cultural and symbolic relationships within which substance consumption is contextualized. In other words, focusing on the importance of a "stylization of space" [79] by the subculture, both the Pearl and the Occupied Warehouse can be understood respectively as "an open drug scene" [82] and as an "anti-institutional social center" $[84,85]$ or "political squat" [86,87] where alternative, oppositional and confrontational values and practices are promoted and encouraged as landmarks of the subculture. Moreover, accounting for the locations of the sites at the intersection of touristic spots and working-class housing projects in the case of the Pearl and in the midst of a run-down, post-industrial area in the case of the Occupied Warehouse; and the working-class background of most members and their substantial anti-protestant working ethic, helps to bring into focus the continuing importance of the concept of social class in the study of contemporary youth subcultures (more on social class in the next lines).

Secondly, considering how the sites and their "affective atmospheres" [88] function as catalyzers for subcultural practices and identity processes, helps us to understand their fundamental role 
in how individuals socialize into the subculture and consequently ascribe resistance meanings to substance consumption and other cultural practices. In fact, we have noticed that in both sites substance consumption is at the center of the identity of the subculture, and in both sites substance consumption is substantially framed as providing an alternative to the norms and values of 'mainstream society'. However, while in the case of the Pearl, substance consumption is not only framed in openly oppositional terms but it is also the main identity marker of the subculture, in the case of the Occupied Warehouse substance consumption is nested within a broader network of cultural and political projects, ranging from music production, concerts, art exhibitions to political protests and related activities.

Thirdly, substance consumption is not merely an oppositional practice of differentiation or a further identity marker inscribed within broader sociocultural and political activities, but it expresses also the hedonistic ethos of the subculture. However, the carnivalesque character of evasive and hedonistic bodily practices such as substance taking behaviors-carried out in an either chilled, ecstatic, or cathartic manner-challenges 'the sovereign', that is to say dominant values and morale, by questioning its norms and assumptions. In other words, if Fiske [45] (p. 129) is right in stating that the pleasures of evading or resisting 'the sovereign' are not necessarily progressive or radical, but can be transitional and partial, then when momentary acts of resistance such as substance consumption are transformed in shared cultural practices, their potentially countercultural character over the power relations they inhabit becomes evident.

At this point it is important to underline how the antithetic notions of "politics of resistance" and "politics of existence" [27] seem to coexist, to a certain degree, within the practices of the subculture explored. In fact, although highly normalized within youth popular culture [4-6], the illegal nature of substance consumption makes it difficult to undress this cultural practice of its confrontational and oppositional character even though at times the main reasons behind consumption may be understood as being merely leisure-oriented, hedonistic and substantially a-political in character. Therefore, even if we frame substance consumption in terms of a "politics of existence", in an attempt to confirm "...a personal identity self-fulfilled and self-defined as singular, authentic, creative and free" [27] (p. 75), we cannot overlook its explicit confrontational style, at least for the working-class subculture explored. On the contrary, however, some members of the subculture, especially those actively participating in the artistic and aesthetic scene of the Warehouse, may be said to closely embody a "politics of existence" as understood by Ferreira [27]. These members, in addition to participating in the consumption sphere of the subculture, also actively participate in its production, managing to obtain an economic return-albeit a marginal one-from their performances. Needless to say, the symbolic return of their performances is substantially higher than the economic one, and as Ferreira [27] underlines, may function as an important form of self-affirmation for these young people.

Moreover, and in agreement with others [19,28,41-43], I believe that the work of the CCCS is still of help in understanding today's processes of identity construction and resistance practices among young people. For instance, Martin's [28] "critical cultural criminology" of youth suggests that traditional concepts of the CCCS, namely social class, subculture and resistance, are still well-suited theoretical tools. Such concepts can indeed help account for young people's differentiated attempts to seize control over their lives, especially in the context of disadvantaged and marginalized young people. In fact, the employment of these concepts may allow us to examine subcultural practices in a context in which class still matters. For example, and in reference to the case study discussed, the subculture's working-class background seems to influence the manners in which young people are explicitly socialized to the acquisition of specific capitals and resources in order to secure individual identification and values [20] (p. 58) and group belonging. These processes of identification, value ascriptions and group belonging are openly framed in confrontational and resisting terms towards the norms of 'mainstream society' and towards what the subculture's members perceive to be the 'exploitative system of capitalist production'.

Unfortunately, considering the covert nature of the observations, this article is limited in his analytical potentials. This is true specifically in relation to the lack of interviews that might have allowed 
me to explore in more details the working-class background of the subculture's members. However, I would like to underline, following Martin's "critical cultural criminology" and its attention towards capitalist relations of production and consumption, and of course in line with the CCCS's research program [23-26] and more recent studies on Italian youth anti-institutional political subcultures [84-86], the importance of the working-class heritage and ideological commitments of the subculture explored. In fact, Martin's work, due to its sensitivity to capitalism as the overall framework within which we ought to understand cultural and subcultural practices, facilitates our appreciation of subcultures' displays of resistance and attempts of differentiation from mainstream society. In the case of the subculture explored, and in line with the work of the CCCS, these fragmentary and partial attempts to resist the capitalist system of production and consumption as much as the subculture's identity markers are mainly provided by substance consumption itself. Moreover, the more recent literature concerned with Italian youth anti-institutional political subcultures [84-86] provides us with, again contrary to Ferreira's [27] argument that sees youth subcultures as substantial a-political, a more politicized picture of contemporary subcultures. Here, "today's society is characterized by injustice, rooted in particular in social inequalities - and a consequent distribution of power-mainly connected with capitalism" [86] (p.9). In this light, the subculture's rejection of the values and norms of 'mainstream society' has to be understood also as a consequence of the working-class positioning of the subculture and its reactions and resistances towards capitalist power relations of consumption and production.

Concluding, I believe that a broader understanding of substance consumption as a socially and culturally contextualized practice within specific groups and spaces, and especially in relation to working-class youth, may be of crucial importance for scholarly investigations of youth cultures and subcultures. In fact, taking into account issues of class, subculture and resistance, in order to provide a vision of youth popular culture that is also able to include and portray the experiences of young people in more disadvantaged positions and not merely conflating every subcultural experience to a supposedly emerging global youth culture is an important aspect of the argument provided in this paper. In this way, rather than primarily focusing on theoretical debates regarding the actuality of concepts such as subculture and resistance, scholars may instead attempt to understand how youth popular culture is not an homogeneous phenomena at all, and in certain subcultural manifestations the role of CCCS conceptual tools may still maintain their heuristic values.

Despite its covert methodology and its primarily descriptive character, this research has attempted to discuss the normalization of marijuana and hashish consumption within the working-class subculture explored, especially inquiring into its alternative forms of socialization without framing them in 'deviant' terms. I think this is an important task, for it allows us to; firstly, confront the limits of the contemporary "subculture versus post-subcultures debate", insofar as this debate favors academic and theoretical discussions over empirical reality and its heterogeneity; secondly, re-actualize some of the central tenets of the CCCS, which may in turn give justice to the complexity of empirical cases such the one here discussed; and thirdly, to provide a non-pathologic or deviant understanding of substance consumption behaviors. Finally, it is important to notice that the results of this research may be triangulated and re-contextualized within the framework of plausible future inquiries into the subculture, this time adopting a different methodological design based on an overt access to the field. This would also guarantee the possibility to conduce a number of interviews with members of the subculture, thus further unveiling the role and meanings that they ascribe to substance consumption.

Funding: This research received no external funding.

Acknowledgments: I would like to thank my friends and colleagues Lorenzo Pedrini and Nicolas Zampiero for their generous support with an earlier draft of this manuscript and the two anonymous reviewers whose comments greatly contributed to improve the methodological and the substantive arguments put forth in the paper.

Conflicts of Interest: The authors declare no conflict of interest. 


\section{References}

1. Hammersley, R.; Jenkins, R.; Reid, M. Cannabis Use and Social Identity. Addict. Res. Theory 2001, 9, $133-150$. [CrossRef]

2. Dahl, S.L.; Heggen, K. Negotiating Identities: Patterns of Self-presentations among Socially Integrated Cannabis Users. Young 2014, 22, 381-398. [CrossRef]

3. Riley, S.; Morey, Y.; Griffin, C. The 'pleasure citizen'. Analyzing partying as a form of social and political participation. Young 2010, 18, 33-54. [CrossRef]

4. Parker, H.; Measham, F.; Aldridge, J. Drugs Futures: Changing Patterns of Drug Use Amongst English Youth; Institute for the Study of Drug Dependence: London, UK, 1995.

5. Parker, H.; Aldridge, J.; Measham, F. Illegal Leisure: The Normalisation of Adolescent Recreational Drug Use; Routledge: London, UK, 1998.

6. Parker, H.; Williams, L.; Aldridge, J. The normalization of "sensible" recreational drug use: Further evidence from the North West England Longitudinal Study. Sociology 2002, 36, 941-964. [CrossRef]

7. Becker, H. Becoming a Marihuana User. Am. J. Sociol. 1953, 59, 235-242. [CrossRef]

8. Harling, M.R. The place and meaning of 'controlled', illicit substance use in the private lives of a group of individuals. J. Subst. Use 2007, 12, 1-12. [CrossRef]

9. Hunt, G.P.; Evans, K.; Kares, F. Drug use and meanings of risk and pleasure. J. Youth Stud. 2007, 10, 73-96. [CrossRef]

10. Duff, C. Party drugs and party people: Examining the 'normalization' of recreational drug use in Melbourne, Australia. Int. J. Drug Policy 2005, 16, 161-170. [CrossRef]

11. Measham, F.; Parker, H.; Aldridge, J. Dancing on Drugs: Risk, Health and Hedonism in the British Club Scene; Free Association Books: London, UK, 2000.

12. Measham, F.; Moore, K. Repertoires of distinction: Exploring patterns of weekend polydrug use within local leisure scenes across the English night time economy. Criminol. Crim. Justice 2009, 9, 437-464. [CrossRef]

13. Measham, F.; Shiner, M. The legacy of 'normalisation': The role of classical and contemporary criminological theory in understanding young people's substance use. Int. J. Drug Policy 2009, 20, 502-508. [CrossRef]

14. Rojek, C. Leisure and Culture; Palgrave: New York, NY, USA, 2000.

15. Sanders, B. Young people, clubs and drugs. In Drugs, Clubs and Young People: Sociological and Public Health Perspectives; Sanders, B., Ed.; Ashgate: Aldershot, UK, 2006; pp. 1-11.

16. Soar, K.; Turner, J.; Parrott, A. Problematic versus non-problematic ecstasy/MDMA use: The influence of drug usage patterns and pre-existing psychiatric patterns. J. Psychopharmacol. 2006, 20, 417-424. [CrossRef] [PubMed]

17. Sanders, B. Gang youth, substance use, and drug normalization. J. Youth Stud. 2012, 15, 978-994. [CrossRef] [PubMed]

18. Lalander, P.; Sernhede, O. Social mobilization or street crimes: Two strategies among young urban outcasts in contemporary Sweden. Educare 2011, 2, 99-121.

19. Shildrick, T. Youth culture, subculture and the importance of neighbourhood. Young 2006, 14, 61-74. [CrossRef]

20. Tolonen, T. Youth Cultures, Lifestyles and Social Class in Finnish Contexts. Young 2013, 21, 55-75. [CrossRef]

21. Ravn, S.; Demant, J. Figures in Space, Figuring Space: Towards a Spatial-symbolic Framework for Understanding Youth Cultures and Identities. Young 2017, 25, 252-267. [CrossRef]

22. Blackman, S. Youth subcultures, normalization and drug prohibition: The politics of contemporary crisis and change? Br. Politics 2010, 5, 337-366. [CrossRef]

23. Hoggart, R. The Uses of Literacy: Aspects of Working-Class Life with Special References to Publications and Entertainments; Chatto and Windus: London, UK, 1957.

24. Clarke, J.; Hall, S.; Jefferson, T.; Roberts, B. Subcultures, Cultures and Class: A Theoretical Overview. In Resistance Through Rituals: Youth Subcultures in the Post-War Britain; Hall, S., Jefferson, T., Eds.; Hutchinson: London, UK, 1993; pp. 9-74.

25. Hall, S.; Jefferson, T. Resistance Through Rituals: Youth Subcultures in the Post-War Britain; Hutchinson: London, UK, 1976.

26. Murdock, G.; McCron, R. Youth and Class: The Career of Confusion. In Working Class Youth Culture; Mungham, G., Pearson, G., Eds.; Routledge: London, UK, 1976; pp. 10-26. 
27. Ferreira, V.S. Aesthetics of Youth Scenes: From Arts of Resistance to Arts of Existence. Young 2016, $24,66-81$. [CrossRef]

28. Martin, G. Subculture, style, chavs and consumer capitalism: Towards a critical cultural criminology of youth. Crime Media Cult. 2009, 5, 123-145. [CrossRef]

29. Blumer, H. What is Wrong with Social Theory. Am. Sociol Rev. 1954, 18, 3-10. [CrossRef]

30. Cuzzocrea, V.; Mandich, G. Students' narratives of the future: Imagined mobilities as forms of youth agency? J. Youth Stud. 2016, 19, 552-567. [CrossRef]

31. Furlong, A.; Cartmel, F. Young People and Social Change: New Perspectives, 2nd ed.; Open University Press: Maidenhead, UK, 2007.

32. Woodman, D.; Bennett, A. Youth Cultures, Transitions, and Generations: Bridging the Gap in Youth Research; Palgrave Macmillan: Basingstoke, UK, 2015.

33. Bennett, A. The post-subcultural turn: Some reflections 10 years on. J. Youth Stud. 2011, 14, 493-506. [CrossRef]

34. Muggleton, D.; Weinzierl, R. The Post-Subcultures Reader; Berg: Oxford, UK, 2003.

35. Maffesoli, M. The Time of the Tribes: The Decline of Individualism in Mass Society; Sage: London, UK, 1996.

36. Bennett, A. Subcultures or Neo-Tribes? Rethinking the Relationship between Youth, Style and Musical Taste. Sociology 1999, 33, 599-617. [CrossRef]

37. Bennett, A. Popular Music and Youth Culture: Music, Identity and Place; Palgrave Macmillan: London, UK, 2000.

38. Miles, S.H. Youth Lifestyles in a Changing World; Open University Press: Buckingham, UK, 2000.

39. Berzano, L.; Genova, C. Lifesyles and Subcultures: History of a New Perspective; Routledge: New York, NY, USA, 2015.

40. Bennett, A. In Defence of Neo-tribes: A Response to Blackman and Hesmondhalgh. J. Youth Stud. 2005, 8, 255-259. [CrossRef]

41. Hesmondhalgh, D. Subcultures, Scenes or Tribes? None of the Above. J. Youth Stud. 2005, 8, 21-40. [CrossRef]

42. Blackman, S. Youth Subcultural Theory: A Critical Engagement with the Concept, Its Origins and Politics, from the Chicago School to Postmodernism. J. Youth Stud. 2005, 8, 1-20. [CrossRef]

43. Shildrick, T.; McDonald, R. In Defence of Subculture: Young People, Leisure and Social Division. J. Youth Stud. 2006, 9, 125-140. [CrossRef]

44. Johansson, T.; Lalander, P. Doing resistance-Youth and changing theories of resistance. J. Youth Stud. 2012, 15, 1078-1088. [CrossRef]

45. Fiske, J. Understanding Popular Culture, 2nd ed.; Routledge: New York, NY, USA, 2010.

46. UrbiStat (2019) Province of Genova. Demographic Data (2017). Available online: https://ugeo.urbistat.com/ AdminStat/en/it/demografia/dati-sintesi/genova/10/3 (accessed on 14 August 2019).

47. Scaramuzzino, R. Equal Opportunities? In A Cross-National Comparison of Immigrant Organizations in Sweden and Italy; Faculty of Health and Society: Malmö, Sweden, 2012.

48. Dal Lago, A.; Quadrelli, E. La Città e le Sue Ombre: Crimini, Criminali e Cittadini; Feltrinelli: Milano, Italy, 2003.

49. Lahtinen, H.; Sirniö, O.; Martikainen, P. Social class and the risk of unemployment: Trends, gender differences and the contribution of education. Acta Sociol. 2018, 1-17. [CrossRef]

50. Dougherty, D.S.; Rick, J.M.; Moore, P. Unemployment and social class stigmas. J. Appl. Commun. Res. 2017, 45, 495-516. [CrossRef]

51. Hill, D. Social Class and Edication. In Considering Class: Theory, Culture and Media in the 21st Century; O’Neil, D., Wayne, M., Eds.; Brill: Leiden and Boston, MA, USA, 2017; pp. 31-50.

52. Dunning, E. Towards a Sociological Understanding of Football Hooliganism as a World Phenomenon. Eur.J. Crim. Pol.Res. 2000, 8, 141-162. [CrossRef]

53. Dunning, E.G.; Maguire, J.A.; Murphy, P.J.; Williams, J.M. The social roots of football hooligan violence. Leisure Stud. 1982, 1, 139-156. [CrossRef]

54. Armstrong, G.; Harris, R. Football Hooligans: Theory and Evidence. Sociol. Rev. 1991, 39, 427-458. [CrossRef]

55. La Pastina, A. The Implications of an Ethnographer's Sexuality. Qual. Inq. 2006, 12, 724-735. [CrossRef]

56. Wall, S. Focused Ethnography: A Methodological Adaptation for Social Research in Emerging Contexts. FQS 2015, 16. [CrossRef]

57. Van Mannen, J. Tales of the Field: On Writing Ethnography; University of Chicago Press: London, UK, 1988.

58. Glaser, B.G.; Strauss, A.L. The Discovery of Grounded Theory: Strategies for Qualitative Research; Aldine Publishing: Chicago, IL, USA, 1967. 
59. Roulet, T.J.; Gill, M.J.; Stenger, S.; Gill, D.J. Reconsidering the Value of Covert Research: The Role of Ambiguous Consent in Participant Observation. ORM 2017, 20, 487-517. [CrossRef]

60. Bulmer, M. The Chicago School of Sociology: Institutionalization, Diversity, and the Rise of Sociological Research; University of Chicago Press: Chicago, IL, USA, 1986.

61. Davis, F. The Cabdriver and his Fare: Facets of a Fleeting Relationship. Am. J. Sociol. 1959, 65, 158-165. [CrossRef]

62. Roy, D. Quota restriction and goldbricking in a machine shop. Am. J. Sociol. 1952, 57, 427-442. [CrossRef]

63. Becker, H.S. The professional dance musician and his audience. Am. J. Sociol. 1951, 57, 136-144. [CrossRef]

64. Humphreys, L. The Tearoom Trade: Impersonal Sex in Public Places; Aldline Press: Chicago, IL, USA, 1970.

65. Bernstein, E.S. The transparency paradox a role for privacy in organizational learning and operational control. Adm. Sci. Q. 2012, 57, 181-216. [CrossRef]

66. Goffman, E. Asylums: Essays on the Social Situation of Mental Patients and Other Inmates; Doubleday Anchor: New York, NY, USA, 1961.

67. Parker, H.J. View from the Boys: A Sociology of Down-Town Adolescents, 2nd ed.; Gregg Revivals: Princeton, NJ, USA, 1992.

68. Pearson, G. The researcher as hooligan: Where 'participant' observation means breaking the law. Int. J. Soc. Res. Method 2009, 12, 243-255. [CrossRef]

69. Goffman, A. On the Run: Fugitive Life in an American City; The University of Chicago Press: Chicago, IL, USA, 2014.

70. Van Amstel, H. The ethics and arguments surrounding covert research. Soc. Cosmos 2012, 4, 21-26.

71. Bulmer, M. When is disguise justified? Alternatives to covert participant observation. Qual. Sociol. 1982, 5, 251-264. [CrossRef]

72. Leo, R.A. Trial and tribulations: Courts, ethnography, and the need for an evidentiary privilege for academic researchers. Am. Sociol. 1995, 26, 113-134. [CrossRef]

73. Lauder, M.A. Covert participant observation of a deviant community: Justifying the use of deception. J. Contemp. Relig. 2003, 18, 185-196. [CrossRef]

74. Lalander, P. Hooked on Heroin: Drugs and Drifters in a Globalized World; Berg: Oxford, UK, 2003.

75. Baumrind, D. Research using intentional deception: Ethical issues revisited. Am. Psychol. 1985, 40, 165-174. [CrossRef] [PubMed]

76. Walters, S.R.; Godbold, R. Someone Is Watching You: The Ethics of Covert Observation to Explore Adult Behaviour at Children's Sporting Events. J. Bioethical. Inq. 2014, 11, 531-537. [CrossRef]

77. Nyberg, D. The morality of everyday activities: Not the right, but the good thing to do. J. Bus. Ethics 2008, 81, 587-598. [CrossRef]

78. Halloy, A. Full Participation and Ethnographic Reflexivity: An Afro-Brazilian Case Study. J. Study Relig. Exp. 2016, 2, 7-24.

79. Ferrero Camoletto, R.; Genova, C. Alternative spatial styles. An exploration of socio-spatial youth cultures in Turin. In Enabling Urban Alternatives. Crises, Contestation, and Cooperation; Fisker, J.K., Chiappini, L., Pugalis, L., Bruzzese, A., Eds.; Palgrave MacMillan: New York, NY, USA, 2019; pp. 179-200.

80. Boccagni, P.; Lagomarsino, F. Transnazionalizmo e Percorsi Familiari: Profili di Genere e di Generazione a Confronto Nell'Immigrazione Equadoriana. Stud. Sociol. 2011, 49, 395-444.

81. Castellani, S. Crisi e risorse familiari. Processi di riproduzione e agency tra giovani figli di ecuadoriani a Genova. Mondi Migr. 2014, 83-104. [CrossRef]

82. Lagomarsino, F.; Castellani, S. The unseen protagonists. Ecuadorians' daughters between Ecuador and Southern Europe. Soc. Identities 2016, 2, 291-306. [CrossRef]

83. Kemmesies, U. The Open Drug Scene and the Safe Injection Room Offers in Frankfurt am Main 1995: Final Report; InstitutzurForderungqualitativerDrogenforschung, AkzeptierenderDrogenarbeit und Rationale Drogenpolitik: Munster, Germany, 1999. Available online: https://trove.nla.gov.au/version/39636716 (accessed on 14 August 2019).

84. Mudu, P. At the Intersection of Anarchists and Autonomists: Autogestioni and CentriSociali. ACME Int. E J. Crit. Geogr. 2012, 11, 413-438.

85. Casaglia, A. Territories of Struggle: Social Centres in Northern Italy Opposing Mega-Events. Antipode 2018, 50, 478-497. [CrossRef] 
86. Genova, C. Youth Activism in Political Squats between Centri Sociali and Case Occupate. Societies 2018, 8, 77. [CrossRef]

87. Martínez López, M.A. The Urban. Politics of Squatters' Movements; Palgrave Macmillan: New York, NY, USA, 2018; ISBN 978-1-349-95314-1.

88. Brennan, T. The Transmission of Affect; Cornell University Press: Ithaca, NY, USA, 2004.

89. Seyfert, R. Beyond Personal Feelings and Collective Emotions: Toward a Theory of Social Affect. Theory Cult. Soc. 2012, 29, 46. [CrossRef]

90. Rose, N. Inventing Our Selves: Psychology, Power, and Personhood; Cambridge University Press: Cambridge, UK, 1996.

91. Durkheim, E. The Elementary Forms of Religious Life, 3rd ed.; Oxford University Press: New York, NY, USA, 2001.

92. Goffman, E. Behavior in Public Places: Notes on the Social Organization of Gatherings; The Free Press: New York, NY, USA, 1963.

93. Wenger, E. Communities of Practice, Learning, Meaning and Identity; Cambridge University Press: Cambridge, UK, 1998.

94. Howard, B. Outsiders. Studies on the Sociology of Deviance; The Free Press: New York, NY, USA, 1963.

95. Genova, C. Social practices and lifestyles in Italian youth cultures. JMIS 2018, 23, 75-92. [CrossRef]

96. Bourdieu, P. Distinction: A Social Critique of the Judgement of Taste; Routledge: London, UK, 1984.

97. Kandel, D. Stages in adolescent involvement in drug use. Science 1975, 190, 912-914. [CrossRef]

98. Kandel, D.B.; Yamaguchi, K.; Chen, K. Stages of progression in drug involvement from adolescence to adulthood: Further evidence for the gateway theory. J. Stud. Alcohol 1992, 53, 447-457. [CrossRef]

99. Mellor, P.A.; Schilling, C. Re-Forming the Body. Religion, Community and Modernity; Sage: London, UK, 1997.

(C) 2019 by the author. Licensee MDPI, Basel, Switzerland. This article is an open access article distributed under the terms and conditions of the Creative Commons Attribution (CC BY) license (http://creativecommons.org/licenses/by/4.0/). 